\title{
O VAMPIRO NA LITERATURA: UM ESTUDO SOBRE A CONSTITUIÇÃO DA PERFORMANCE DA PERSONAGEM ATRAVÉS DA PERMUTABILIDADE DO TEMA
}

\author{
Juliana Porto Chacon Humphreys ${ }^{1}$
}

\begin{abstract}
RESUMO: Os vampiros têm sido personagens recorrentes nas histórias fantásticas de horror. Nesse percurso as criaturas sugadoras de sangue do sexo masculino passaram a apresentar não somente compleição física estereotipada, mas, principalmente, performances que delimitam o protagonismo e determinam a função dessas personagens. $\mathrm{O}$ objetivo deste estudo é propor uma classificação dos vampiros literários, buscando compreender como a permutabilidade da temática vampiresca conformou as performances através da literatura de horror, culminando no romance Drácula de Bram Stoker de 1897, principal responsável pela transmutação da personagem da literatura para o cinema e referência para o que se entende por vampiro atualmente. A classificação é feita a partir de oito textos que possibilitam o destaque de três fases do vampiro literário: o folclórico, o byroniano e o stokeriano. Cada uma dessas fases carrega aportes da fase anterior e, através de trechos dos textos, é possível destacar o pontos essenciais dos padrões do vampiro que são permutados entre as histórias, sendo que o romantismo-gótico dos séculos XVIII e XIX é a última etapa englobada neste texto. A premissa para o levantamento proposto é a teoria sobre a permutabilidade do tema, proposta por Vladimir Propp para o estudo da morfologia dos contos maravilhosos. Por mais ensaística que possa parecer esta empreitada, o estudo é um recorte de uma extensa pesquisa que utilizou dezenas de textos para estabelecer os critérios de classificação. Aqui são apresentados os mais relevantes na compreensão dessas figuras perpetuadas pelas histórias fantásticas de horror.
\end{abstract}

PALAVRAS-CHAVE: Vampiro. Horror. Permutabilidade do tema. Romantismo. Literatura gótica.

\section{A PERMUTABILIDADE DA TEMÁTICA VAMPIRESCA}

A figura do vampiro romântico gótico e o enredo que a envolve são resultado de uma permutabilidade temática que, ao longo de pouco mais de um século, amalgamou não só características físicas e comportamentais ao vampiro masculino, como também delineou cenários para a trama vampiresca, originou cacoetes de performance, instituiu rituais de ataque e aniquilamento, efluiu vícios de diálogos e desfechos previsíveis.

A conformação através dos textos é um fenômeno mais ou menos comum às criaturas sobrenaturais como, por exemplo, os lobisomens e zumbis, mas, em termos vampirescos, o que se percebe é que a permutabilidade do tema (PROPP, 2006) foi vital para a conformação arquetípica da personagem, sobre a qual se constituiu, inclusive, boa parte do plano geral do gênero horror.

A permutabilidade do tema diz respeito a qualidades de uma determinada personagem, bem como a suas funções, que são transmitidas de um conto a

\footnotetext{
${ }^{1}$ Doutora em Comunicação e Semiótica pela Pontifícia Universidade Católica de São Paulo, PUC/SP.Email: juliana@humphreys.com.br
}

Revista de Letras JUÇARA, Caxias - Maranhão, v. 02, n. 01, p. 312 - 331, jul. 2018 | 312 
outro, de uma narrativa a outra, embasando a estrutura textual em todos os níveis, estabelecendo uma espécie de padrão nos contos de mesmo tema. Não há dúvidas de que a recorrência da performance e da atmosfera vampiresca através dos textos pré-românticos e romântico góticos foi determinante para a conformação da figura vampiresca como um todo.

Vale ressaltar que a questão da permutabilidade do tema abordada na obra Morfologia do Conto Maravilhoso (PROPP 2006), foi pensada para edificar uma morfologia dos contos maravilhosos, sendo esse um ponto de partida para reconhecimento de tópicos distintos como, por exemplo, as funções, as sequências, as personagens e os motivos para ação, dentre outros tópicos que permeiam as histórias, constituindo uma espécie de paradigma dos contos maravilhosos. Não é objetivo deste estudo construir uma morfologia dos textos vampirescos, essa por si só seria tarefa suficiente para tomar as páginas que aqui se escrevem, mas, no entanto, a técnica introduzida por Propp é de grande inspiração e serve de princípio para uma classificação simplificada dos vampiros, a partir do arcabouço de textos oriundos do Romantismo-gótico, até chegar ao romance Dracula (STOKER 1897), uma das responsáveis pela transmutação do vampiro literário para o cinematográfico, sendo assim, para efeito desse artigo, esse será o ponto final de análise e o foco a ser perseguido durante toda a construção da explanação.

\section{OS DECADENTES SUGADORES NA LITERATURA ROMÂNTICA-GÓTICA DOS SÉCULO XVIII E XIX}

Nos séculos XVIII e XIX, o sentimento de horror desdobrou-se entre 0 horror real e o horror projetado. $O$ século $X X$ foi o século do horror como um gênero específico. $O$ horror, o sobrenatural e o sinistro ocuparam as pinturas, as páginas literárias e, mais adiante, as telas de cinema. O medo como resultado de uma ação deliberadamente artística foi objeto de entretenimento dos mais rentáveis.

A internacionalização da literatura romântica correspondeu a uma massificação da literatura na Europa e nos Estados Unidos. Não de toda ela, é óbvio; mas de um tipo específico de novelas e contos, um "subgênero" do 
Romantismo denominado Gótico, que animou para todo sempre as personagens vampirescas.

Mais do que isso, os vampiros, da forma como são conhecidos hoje, são fruto desse movimento literário que levantava canetas e pincéis contra a estética clássica e que era o retrato de uma Europa sentimental e melancólica do século XVIII.

Se o Romantismo primava pelo macabro, pelo terrificante, pelo desordenado e pelo estranho (PRAZ 1996), então o Gótico o complementa agregando a tristeza, a decadência, a angústia e o sombrio a essa atmosfera grotesca de morte e beleza.

O romance Gótico caracterizou-se por ser uma literatura feita por intelectuais para o deleite das massas. Independente de ter sido um movimento genuíno ou fabricado, o Gótico extrapolou qualquer expectativa de sucesso, tornando-se um estilo voltado, desde o começo, para o entretenimento. Essa vocação do Gótico para a recreação confirma-se ainda hoje nos materiais derivados do gênero.

O Gótico é a literatura dos castelos antigos e da Europa Medieval; é também o estilo da atmosfera sombria, da decadência, dos fantasmas e aparições. Encontra-se ainda nessa literatura, o mistério e a tendência inquestionável ao horror sobrenatural. Efetivamente, essa era a combinação perfeita para um público semiculto que carecia de ferramentas para a distração. Não há como ignorar a presença da religião como elemento de horror nas novelas góticas, especialmente os rituais e símbolos católicos, as catedrais e os eclesiásticos.

Da frutífera fase do gótico inglês do século XVIII, surge a figura do poeta Lord Byron, um epítome da essência e dos ideais góticos. Sua contribuição literária foi de certo modo, abafada pelo estilo de vida do poeta, que levava a cabo a noção de liberdade individual idealizada pelos artistas do movimento.

A figura e o estilo de vida de Lord Byron, o medievalismo idealizado, a concentração em torno do mórbido e do sombrio, trouxeram à tona temas como 0 Duplo e o vampirismo, que por sua adequação ao estilo, tornaram-se ícones do Gótico, por sua vez, inserido no contexto do Romantismo. 
É óbvio que o vampirismo não é novidade dos movimentos em questão, afinal, seres sugadores de sangue e de energia vital estão presentes em todas as culturas, incluindo as milenares mitologias orientais. Mesmo o Duplo ou espectros que refletem o Outro não são novidades, mas na literatura, os alemães dominaram o tema do Duplo com tal maestria, como poucas vezes pôde ser testemunhado como na obra Fausto, de Goethe. De certa maneira vampiros e Duplos são parentes próximos e cabe alocá-los no mesmo grupo temático.

O vampiro pré-literário de meados do século XVIII era um ser repugnante, que dificilmente seria convidado para um jantar ou roda social: unhas compridas, barba malfeita, boca e olho esquerdo abertos, rosto vermelho e inchado, envolto em sua mortalha. (ARGEL, NETO, 2008. p. 21)

Somente a partir de uma mutação influenciada pelo movimento Romântico gótico é que o vampiro evoluiu até a criatura que se assemelha a um homem, com apelos sensuais e aristocráticos. Essa transição culminou com a escrita e o lançamento do romance Drácula de Bram Stoker, responsável pela transmutação do vampiro literário para o cinematográfico, porém, mais importante, responsável pela popularidade das figuras vampirescas durante todo o século XX e início do XXI, exercendo uma performance amalgamada quase que totalmente por esse romance que, sabiamente, bebeu nas fontes que 0 antecederam.

O irlandês Bram Stoker (1847-1912), começou a trabalhar no romance Drácula em 1890, data das primeiras anotações do autor sobre o assunto. Foram sete anos de trabalho, nos quais se debruçou em enorme quantidade de material coletada por ele durante esse período.

A primeira edição de Drácula foi lançada em 1897, porém apesar do relativo sucesso do romance, em 1901 Bram Stoker promoveu algumas alterações no texto original. Não se sabe as razões corretas para tal feito, mas alguns estudiosos especulam que Stoker percebeu que a versão que estava em circulação era muito extensa e expunha de forma categórica aspectos negativos das personagens oponentes de Drácula. Essa versão resumida é a que permanece em circulação atualmente.

\section{CLASSIFICAÇÃO DO VAMPIRO ATRAVÉS DA PERMUTABILIDADE DO TEMA}


A classificação partirá das idiossincrasias do vampiro nas três fases distintas do vampiro literário romântico gótico: vampiro folclórico, vampiro byroniano e vampiro stokeriano. Esse desmembramento é proposto para que seja possível reconhecer as peculiaridades da figura do vampiro estabelecidas em função de padrões característicos de cada uma das fases.

A seguir, as abordagens relativas a cada uma das fases do vampiro romântico gótico, a saber: o vampiro folclórico, o vampiro byroniano e o vampiro stokeriano.

O primeiro é o vampiro folclórico, ou seja, aquele que insere na literatura romântica a criatura vampiresca com respaldo nas crenças eslavas. Um olhar superficial pelas mitologias mais antigas da Humanidade revela a presença unissonante de criaturas que se alimentam do sangue vivo de humanos e animais para preservar suas existências. Nessas mitologias, os sanguessugas representam seres monstruosos distintos da concepção de morto-vivo conhecida atualmente. Especificamente na mitologia eslava, influenciada por crenças e folclores das pequenas regiões do interior da Europa oriental, é que os sanguessugas (vurdalaki, upyr, brucolaquis) começam a adquirir os contornos de um morto que retorna para sugar o sangue de parentes e pessoas próximas. Apesar de, claramente, os vurdalakis e upiros representarem uma forma de condenação ao morto regressante, o vampiro folclórico revela-se muito mais um problema para aquele que é assombrado constantemente pelas aparições do morto do que, efetivamente, para aquele que regressa.

Assim, ainda não havia no vampiro eslavo toda a complexa simbologia em torno da dualidade religiosa céu-inferno, alma-corpo, salvação-condenação, que se constitui nas fases posteriores. Por enquanto, o vampiro é uma assombração com poderes letais, sem a complexidade intentada por outros vampiros românticos. Os vurdalakis e ou regressantes são como uma doença e devem ser exterminados, representam o perigo e o medo, além da tristeza de presenciar um conhecido naquela situação catastrófica, fora isso, para o vampiro, o que se tem é fome, nada mais além disso.

Três textos podem ser apontados como as principais bases para a divulgação do vampiro folclórico da Europa oriental para a ocidental. 
O primeiro dele é a Dissertação sobre os regressantes em corpo, os excomungados, os upiros ou vampiros, brucolaques, etc, escrito por Dom Augustin Calmet, em 1746. Este é o texto que insere o folclore eslavo vampiresco na corrente literária romântica-gótica. Trata-se de um compêndio de casos envolvendo vampiros que, de forma decisiva, ampliou o interesse por essas figuras chupadoras de sangue. A importância do compêndio de Calmet, no contexto do vampiro literário, não é novidade:

\begin{abstract}
"Ao escolher, traduzir e editar uma seleção desses escritos (também ela uma antologia a seu modo), ele acabou não só divulgando diversos textos e autores associados ao tema, como também introduzindo o próprio assunto no salão, de forma decisiva. Em outras palavras, com Calmet, a discussão - que vinha progressivamente delineando o vampiro e diferenciando-o de outros demônios, espectros e mortos-vivos, com especial força a partir dos anos 1730 - sai dos meios oficiais ou universitários (jurídicos, médicos, teólogos) e ganha um público bem mais amplo. Que isso tenha acontecido na França do século XVIII não é gratuito." (CARVALHO, 2010, p. 24)
\end{abstract}

Em termos de trajetória para conformação do vampiro, a importância da Dissertação de Calmet é referente, primeiramente, à função da personagem ${ }^{2}$, isto é, à uma tradução textual das tradições orais que até aquele momento prevaleciam em relação ao folclore dos regressantes. Desses relatos, o vampiro delimitou seu campo de ação, apresentando seus métodos, bem como as condições para sua atuação.

Outro texto é o Crê a moça minha amada (O Vampiro), de Henrich August Ossenfelder, de 1748. A poesia de H. August Ossenfelder introduz um importante elemento à função do vampiro: o amor, ou seu correlato, o sexo; verdadeiramente, a conotação de uma relação íntima entre um humano e uma criatura sobrenatural, com aspectos de desejo e lascividade, que mais tarde, será sentido por ambas as partes, por mais que nesse momento seja privilégio do vampiro.

O poema apresenta um vampiro narrador, com tendências sádicas que investe contra uma moça que, imagina-se, é alvo de desejos amorosos do vampiro.

\footnotetext{
2 "Por função compreende-se o procedimento de um personagem, definido do ponto de vista de sua importância para o desenrolar da ação. (...) Os elementos constantes, permanentes, do conto maravilhoso são as funções das personagens, independentemente da maneira pela qual eles as executam. Essas funções formam as partes constituintes básicas do conto." (PROPP, 2006. p. 22)
} 
Nesse poema surge, de forma inédita, a associação entre o sangue e o vinho que marcará a trajetória do vampiro cinematográfico.

O terceiro texto é The Giaour - O Infiel de Lord Byron, de 1813. Primeiramente, é preciso esclarecer por qual razão um poema de Lord Byron aparece alocado na fase do vampiro folclórico e não naquele que, pela própria nomenclatura, caberia às suas produções.

Apesar desta aparente obviedade, Lord Byron apenas inspirou a figura do vampiro byroniano que, mais adiante, será desmistificada. Nesse trabalho, o poeta circula muito mais pelo terreno da criatura folclórica que retorna ao seio familiar do que propriamente, do vampiro sedutor que atua pela sociedade estrangeira.

A sexualidade está presente em $O$ Infiel, começando pelo nome, mas ainda não está adequada às linhas que caracterizam o vampiro byroniano, um lascivo por natureza.

O Infiel utiliza-se das ameaças proferidas pelo próprio narrador para instituir a condenação de um infiel ao sofrimento eterno. Ele não terá o descanso eterno, pois deverá ficar preso em sua sepultura, após retornar ao seio familiar e se negar a tomar o sangue de sua filha.

Em seguida, apresentam-se os aspectos que caracterizam o vampiro folclórico, tendo como o base os três textos apresentados anteriormente.

O primeiro aspecto é a essência da performance vampiresca. Os sanguessugas da mitologia assumem definitivamente o caráter de um morto vivo que se levanta da tumba para sugar o sangue dos seres humanos.

As memórias públicas dos anos de 1693 e 1694 falam de Upiros ou Vampiros ou Regressantes, que são encontrados na Polônia e sobretudo na Rússia. Eles surgem entre meio-dia e meia-noite e vêm sugar o sangue dos homens ou dos animais vivos em tal quantidade, que, às vezes, ele lhes sai pela boca, pelo nariz e principalmente pelas orelhas; e algumas vezes o cadáver boia no sangue extravasado no seu caixão. Diz-se que ele tem uma espécie de fome que o leva a comer o tecido que encontra à sua volta. - (CALMET, 1746). (Grifo nosso)

O segundo é a forma de se reconhecer o vampiro e de matá-lo. vampiro folclórico requer certos rituais para seu extermínio. O método mais importante por representar forte influência aos vampiros posteriores é a abertura do caixão para reconhecimento da criatura e, subsequente ataque com pregos 
nas têmporas. Mais para frente, esse ritual derivará outra mais conhecido: o das estacas no coração e o decepamento da cabeça da criatura.

A partir desse depoimento, o Conde fez desenterrar esse homem e, tendo-o encontrado como o primeiro, o sangue fluido como o de um vivo, ordenou que the enfiassem um grande prego na têmpora e em seguida que o devolvessem ao túmulo, mandou que queimassem um terceiro, que estava enterrado havia mais de dezesseis anos e havia sugado 0 sangue e causado a morte de dois de seus filhos. - (CALMET, 1746). (Grifo nosso)

O terceiro aspecto é a localidade de ação e aniquilamento das vítimas. Através do vampiro folclórico, são delimitadas as regiões suscetíveis à ação dos vurdalakis e correlatos. As mais relevantes, como Hungria e Transilvânia, encontram raízes já nessa fase da literatura. É também nesse momento que o vampiro retorna à vítima por diversas vezes, prolongando o seu sofrimento. Essa recorrência fortalece a face sádica do vampiro, à medida em que ele impinge repetidas torturas mentais e corporais a suas presas, enquanto elas encontram-se em estado sonolento.

Num certo Cantão da Hungria, chamado em latim Oppida Heidonum, além do rio Tisza, vulgo Theyse - ou seja - entre esse rio que banha o afortunado Terroir de Tockay e a Transilvânia -, o povo conhecido como Heiduque crê que certos mortos, por eles chamados de Vampiros, sugam todo o sangue dos vivos, de sorte que estes ficam visivelmente extenuados, enquanto os cadáveres, como sanguessugas, enchem-se tanto de sangue que é possível vê-lo sair de seus caminhos e até suas portas. - (CALMET, 1746). (Grifo nosso)

O quarto é com relação ao regresso do vampiro ao seio familiar e ao vilarejo onde vivia. De todo o acervo de funções do vampiro folclórico, o traço mais marcante dessa figura iminentemente oriental, renegada aos recônditos "estranhos" e exóticos da Europa ocidentalizada, é o fato ela atuar nos pequenos vilarejos e, justamente por isso, retornar ao seio da própria família como uma assombração, porém, nesses casos, com atuação letal. A restrição na área de atuação do vampiro folclórico deve-se ao fato de não haver para essa criatura, tanto em vida quanto em morte, um horizonte que lhe permitisse expandir os limites da convivência e da sobrevivência além-morte.

Os ataques dos vampiros dão-se também contra filhos, esposas e crianças, aumentando o caráter demoníaco de uma criatura que apaga qualquer traço sentimental depois de "passar para o outro lado". 
No início de setembro morreu, na Vila de Kisilova, localizada a três léguas de Gradisch, um velho de sessenta e dois anos. Três dias depois de ser enterrado, ele apareceu à noite a seu filho, pedindo-lhe de comer; após este tê-lo servido, ele comeu e desapareceu. [...] não se sabe se o filho o serviu de novo ou não: mas este foi encontrado morto na cama na manhã seguinte; no mesmo dia, cinco ou seis pessoas da Vila adoeceram subitamente e morreram uma após a outra poucos dias depois. - (CALMET, 1746). (Grifo nosso)

No teu próprio rincão hás de baixar/E o sangue da tua raça ali chupar. A meia-noite, esposa, filha irmã/Dar-te-ão sugadas, o vital elã[...]. (BYRON, 1813). (Grifo nosso)

O quinto e último aspecto do vampiro folclórico é relativo ao ataque no leito da vítima, durante o sono. Os ataques noturnos do vampiro não só ocorrem dentro da própria casa do ex-vivente como, via de regra, efetivam-se no próprio leito da vítima, o que comprova a falta de uma perspectiva derivada da maneira pacata com que os vilarejos orientais levavam a vida.

De ti quero eu vingar-me,/E de um Tokayer, hoje,/Beber a um vampiro./E ao dormires suave, $/ \mathrm{Te}$ sorver à formosa/Face púrpura fresca." (OSSENFELDER - 1748). (Grifo nosso)

A segunda fase de classificação é a do vampiro byroniano, que representa o ápice do vampiro romântico gótico: por um lado, com aspecto estranho, decadente, cínico, apaixonado pelos prazeres da vida e com compleições frágeis, mas, por outro, sinistramente forte, irresistivelmente sensual e com intenso apelo sexual. É também nessa fase que o elemento vingança passa a influenciar as atitudes do vampiro contra seu antagonista.

Apesar do vampiro byroniano ter adentrado o perímetro do Romantismo pelas palavras de John Polidori, essa configuração vampiresca foi totalmente inspirada pela figura de Lord Byron, paciente e amigo de John Polidori, e símbolo máximo do Romantismo-gótico inglês do século XVIII.

Byron, que sabia a fundo a arte de se mettre-en-scène, fez muito para manter a auréola lendária em torno de sua cabeça bela e pálida de um nobre Lorde, rebelde contra as convenções morais da sua terra, excluído da sociedade humana por um crime misterioso, perpetrado no passado falava-se de relações incestuosas com sua meio-irmã. O divórcio repentino, exigido por Lady Byron, pareceu confirmar os boatos. Desde então, o poeta viveu na Itália, entregando-se a orgias fabulosas que roubaram o sono às mulheres da Europa inteira. (CARPEAUX, 2012, p. 1593) 
É contra o vampiro byroniano que o papel da religião começa a ganhar força. Apesar de ainda não constituir propriamente um ritual, alguns critérios para aniquilar um vampiro passam a existir. $O$ que se tem, até esse momento, é apenas um melhoramento das técnicas apresentadas contra o vampiro folclórico.

É também nessa fase que o vampiro torna-se um nobre, um aristocrata que expande seus limites de atuação e, ao contrário dos vurdalakis e regressantes que agiam localmente, o vampiro byroniano sempre está às voltas com estrangeiros, seja viajando do interior oriental para a urbanização ocidental, seja aproveitando-se de aventureiros que cruzam seu caminho.

Além desses aspectos gerais, traços relevantes de suas funções para o enredo, bem como de sua personalidade transformaram-se ao longo da trajetória do vampiro byroniano, através da permutabilidade do tema pelos textos do período Romântico gótico. Para a abordagem desses tópicos foram selecionados dois textos que se seguem.

O primeiro é intitulado O Vampiro e foi escrito por John Willian Polidori em 1819. Esse é o texto que inaugura o momento mais frutífero do vampiro na literatura, no qual, em pouco mais de um ano, obras de grande relevância para o tema foram produzidas, incluindo as duas aqui selecionadas.

O texto de John Polidori é o marco zero do vampiro byroniano gótico, pois Lord Ruthven conseguiu condensar, com seu aspecto físico e com as nuances de seu comportamento, as tendências que discretamente conformavam-se esparsamente em textos anteriores.

$O$ conto $O$ Vampiro, tão fortemente inspirado na figura e no comportamento idealizado de Lord Byron, foi durante muito tempo creditado a ele, devido a uma ironia do destino que fez com que o editor da revista New Monthly Magazine confundisse esse texto com outros de Lord Byron, que se encontravam na mesma remessa. As similaridades eram tantas, que não houve dúvidas que era um trabalho do poeta tão famoso e não de seu médico, com talentos à literatura fantástica.

O Vampiro conta a história do primeiro vampiro nobre da literatura, Lord Ruthven, que seduz mulheres puras e castas, levando-as à devassidão, enquanto ludibria um jovem recém chegado à sociedade inglesa, chamado Aubrey. 
Embevecido pela figura misteriosa do vampiro, Aubrey parte em viagem para a Grécia com seu suposto novo amigo. Num determinado momento, Aubrey descobre as atrocidades que Lord Ruthven faz com as mulheres e com famílias inocentes com as quais cruza, e trai o vampiro alertando uma de suas vítimas. A partir daí, Lord Ruthven passa a se vingar vagarosamente do rapaz, matando a bela amada de Aubrey, a jovem grega lanthe, levando o moço à loucura com suas aparições. Por fim, Lord Ruthven ataca Miss Aubrey, a inocente irmã de seu inimigo, levando os dois irmãos à morte no final da história. Verdadeiramente, Lord Ruthven é um vampiro tão letal quanto socialmente articulado e sensual, levando todos os que cruzam seu caminho à falência, à devassidão, ou ainda, à loucura e, posteriormente, à morte.

Outra obra que se destaca é Augustus Darvell de Lord Byron, de 1819. O fragmento que se apresenta foi publicado pelo editor de Lord Byron com o intuito de desfazer o mal entendido que creditava o conto $O$ Vampiro à sua autoria. Lord Byron tentava mostrar como, efetivamente, seria um texto vampiresco no estilo conto, escrito por ele. Apesar de essa publicação não ter servido aos propósitos de Byron de desmistificar o conto anterior, com Augustus Darvell o poeta amalgamou definitivamente a figura do vampiro romântico gótico à história da literatura. Augustus Darvell é um vampiro com aspecto estranho e misterioso, que exerce atração em um jovem inglês por seus dotes sociais e aparente conhecimento de vida. Os dois tornam-se amigos e, então, partem em viagem rumo ao leste europeu, onde terminam nas imediações da Turquia, em um cemitério de Esmirna. É lá que o fantástico revela-se, fazendo com que Augustus Darvell termine, temporariamente, sua jornada vampiresca, contando com a ajuda de seu jovem amigo para o seu sepultamento.

Tendo como base esses dois textos apresentam-se, a seguir, os aspectos relativos aos padrões do vampiro byroniano.

$\mathrm{O}$ primeiro e mais importante é o apelo sexual do vampiro. $\mathrm{Na}$ fase byroniana do vampiro, o homossexualismo torna-se uma vertente, principalmente em relação às mulheres. Iniciam-se os atos de vampiras atraentes e sensuais que representam todo o sonho da libertação sexual feminina, intrínseco ao movimento gótico. Vampiros e humanos ensaiam orgias que nunca concretizam-se 
explicitamente, mas que fomentam a imaginação tanto das personagens, quanto dos leitores.

Descreveram-no como o reduto dos vampiros em suas orgias noturnas e advertiram-lhe que grandes malefícios recairiam sobre quem ousasse cruzar o caminho deles. - (POLIDORI, 1819). (Grifo nosso)

O segundo diz respeito ao ritual de ataques sucessivos do vampiro às vitimas femininas. Esse é um vampiro que não ataca suas vítima apenas para que possa sugar-Ihes o sangue, a ação do vampiro envolve rituais que servem ao ego da criatura, como numa confirmação do seu poder de sedução. Porém, as vítimas, prioritariamente mulheres, afundam-se em sensações que as fazem liberar todo o instinto sexual reprimido. As vítimas do vampiro byroniano definham paulatinamente, enquanto perdem os sentidos em sonhos dolorosos, mas profundamente prazerosos.

Para aumentar sua satisfação, ele exigira que suas vítimas, as parceiras de sua culpa, se precipitassem do cume da imaculada virtude até o mais baixo abismo da infâmia e da degradação. Em suma, todas aquelas mulheres que ela procurava, aparentemente por causa de suas virtudes, após sua partida deixaram a máscara de lado e não tiveram escrúpulos em expor toda a deformidade de seus vícios ao olhar público. (POLIDORI, 1819). (Grifo nosso)

O terceiro é a recorrente violência do vampiro contra humanos do sexo masculino. O mesmo movimento que levou o vampiro rumo a um contato sexualizado com as vítimas femininas, criou nesse ser uma aversão ao sangue masculino. Dessa forma, com exceções inerentes à homossexualidade, o vampiro romântico gótico tende a mostrar sua face violenta para o homem, renegando 0 contato com seu sangue. Estabelece-se portanto, uma divisão estanque: sedução e sexualidade para mulheres, em busca do consumo de seu sangue; força e violência para homens, com o intuito, unicamente de eliminá-los.

Determinado a vender sua vida tão caro quanto pudesse, ele lutou, mas em vão: foi erguido no ar e arremessado com enorme força contra o chão. Seu inimigo se atirou sobre ele, ajoelhou-se sobre seu peito e colocou as mãos em torno de sua garganta, mas nesse momento foi atingido pelo clarão de muitas tochas vindas de fora. - (POLIDORI, 1819). (Grifo nosso) 
O quarto padroniza a presença de conflitos internos experimentados pelo vampiro byroniano. $O$ vampiro byroniano traz à tona uma criatura que permanece em seu simulacro de vida em meio a conflitos pessoais e vícios morais, muito mais do que complexos em termos de condenação da alma. É nessa fase que alguns vampiros passam a sentir culpa pelos atos cometidos e por experimentarem tamanho prazer em relação às coisas mundanas. A angústia do vampiro é um reflexo da inclinação ao sentimentalismo inerente ao Romantismo e cultuado pelo Gótico. A figura decadente do vampiro byroniano exalta um ser que, ao existir por tanto tempo, encontra-se desgastado por sentimento intrínsecos aos seres humanos.

Das paixões que ele porventura houvesse tido, parecia que algumas estavam extintas e outras concentradas; que os seus sentimentos eram intensos, tive oportunidades suficientes para observar, pois ainda que ele conseguisse controla-los, não conseguia dissimulá-los de todo. (...) Saltava aos olhos que ele era tomado por alguma inquietação sem cura, mas se esta provinha de ambição, amor, remorso, tristeza - de uma dessas coisas ou de todas elas - ou meramente de um temperamento mórbido inclinado à doença, isso eu não pude descobrir. - (BYRON, 1819). (Grifo nosso)

O quinto e último padrão é a viagem como forma de contato como vampiro byroniano. Nessa fase da literatura vampiresca Romântica-gótica, estabelece-se uma convenção interessante em relação à ativação da atmosfera fantástica. É como se o fantástico existisse à parte da vida urbana, principalmente da de Londres, porém, ativada pelas aventuras do estrangeiro inglês incrédulo e curioso, e, acima de tudo, com uma postura arrogante e displicente ante os avisos dos povos locais que convivem com os fenômenos sobrenaturais. Para se ter contato com o vampiro uma viagem deve acontecer: seja do estrangeiro ocidental para a Europa Oriental, seja do vampiro para a sociedade dos grandes centros europeus.

No ano de $17 . .$. , depois de projetar por algum tempo uma viagem por países até então pouco visitados, parti acompanhado de um amigo, a quem designarei por Augustus Darvell. Ele era alguns anos mais velho do que eu, possuía uma fortuna considerável e provinha de família antiga: vantagens que um vasto discernimento o impedia igualmente de subestimar ou sobrevalorizar. - (BYRON, 1819). (Grifo nosso) 
A terceira fase é o vampiro stokeriano que tem como manifestação máxima o romance Drácula, de Bram Stoker, de 1897, de extrema importância por ter sido a primeira obra vampiresca adaptada para o cinema e, consequentemente, por ter influenciado de forma determinante a figura do vampiro perpetuada ao longo do século $\mathrm{XX}$.

O vampiro stokeriano é um legítimo representante do movimento gótico tardio, que ocorreu às portas do século $\mathrm{XX}$, ainda em uma Inglaterra enterrada nos costumes vitorianos. Essa constatação equivale a afirmar que Bram Stoker produziu o vampiro mais importante para o cinema porque pôde beber o sumo dos vampiros que o antecederam, mesclando as referências românticas, os elementos históricos e o contexto social da Inglaterra vitoriana em uma personagem repleta de intertextualidade.

Em primeira instância, o vampiro stokeriano tem um nome: Drácula. Esse batismo perpetuou-se em vampiros posteriores que, de maneira contumaz, assumiram as formas e funções do primeiro, modificando, vez ou outra, alguns detalhes do contexto de atuação da personagem.

Drácula é o retrato acabado do estilo stokeriano, embebido em seus antepassados. Ele é um sanguessuga e um morto regressante, oriundo do leste europeu, aos moldes mais fieis do folclore vampiresco e, é também, um nobre irresistivelmente misterioso, de feições incomuns e forte apelo sexual, assim como um vampiro byroniano clássico.

Porém, o vampiro stokeriano é acima de tudo, mau. À parte as derivações que surgiram na segunda metade do século $X X$, Drácula e seus correlatos não são sentimentais ou melancólicos, assim como não apresentam nenhum sintoma de culpa ou arrependimento. Ao contrário, são ardilosos, articuladamente inteligentes e utilizam de todo seu poder para arranjar os fatos a seu favor.

Drácula é sádico e mantém suas vítimas em lenta agonia, enquanto ele retorna noite após noite para deleitar-se com seu sangue. $\mathrm{O}$ vampiro stokeriano não se relaciona de forma nenhuma com vítimas masculinas, sendo destinado a eles todo o ódio que essa criatura sente pela humanidade.

Há no vampiro stokeriano o desejo contido de obter uma companhia pela eternidade, por isso ele tende a selecionar uma vítima para experimentar de seu 
sangue e um ritual que se assemelha a um acasalamento. Essa criatura mantém ao seu lado concubinas que o auxiliam na disseminação do medo por entre uma atmosfera de sonho e magia.

Stoker construiu a personagem Drácula ao longo de dois textos, um deles é o já mencionado romance de 1897 e o outro, é um trabalho anterior, intitulado 0 Convidado de Drácula, escrito entre 1890 e 1897, que poderia funcionar como 0 primeiro capítulo do romance principal, mas que foi retirado pelo autor e lançado posteriormente. Nele, é possível notar como o poder de Drácula ultrapassa o limite imposto pela necessidade de sua presença, de forma que ele amplia seu poder consideravelmente, tornando-se um ser que consegue manipular acontecimentos de diversas maneiras, seja por convencimento ou por utilização de seus poderes sobrenaturais.

No entanto, apesar da força do arquétipo de Drácula, não há como ignorar que a origem do vampiro stokeriano não está nas mãos de Bram Stoker.

A quintessência desse vampiro encontra-se em um texto alemão, de autoria anônima, intitulado O Estranho Misterioso, de 1853.

As similaridades são inquestionáveis e podem ser encontradas em todos os níveis do texto, inclusive pragmática e sintaticamente. A estrutura e a organização dos fatos e o papel das personagens são, realmente, muito similares, conforme mostra-se a seguir.

O fascínio exercido pelo vampiro em uma vítima feminina. A vítima praticamente se joga aos braços do vampiro, tamanho poder de sedução exercido por sua figura.

\footnotetext{
'Franz disse isso?', perguntou Franiska. 'Então você pode lhe dizer que ele não está enganado. Sim, o esquálido, cadavérico, ressequido e lunático estranho é muito mais interessante para mim do que o meu corado, elegante, cortês e prosaico primo." - (ANÔNIMO, 1853). (Grifo nosso)
}

Inicia-se pelo ataque do vampiro. O vampiro retorna ao leito da vítima sucessivamente, para atacar no hiato entre o sonho e a realidade, causando misturas de prazer e dor. Os ataques continuam ocorrendo no leito, mas, agora, esse fato não se relaciona com a falta de perspectiva e, sim, assume uma conotação sexual. 
Fiquei me revirando na cama, e finalmente foi por pura exaustão que caí no sono. Mas que sono! Um medo interno me percorria incessantemente. (...) Não sei se estava meio adormecida ou acordada. Então sonhei - mas tão nitidamente como se estivesse bem desperta que uma espécie de bruma envolvia o quarto, e em meio a ela surgiu o cavaleiro Azzo. Ele me contemplou por um momento, depois se apoiou num joelho lentamente e estampou um beijo na minha garganta. Seus lábios ficaram pousados ali por longo tempo; senti uma ligeira dor, que foi aumentando até eu não mais suportá-la. Tentei afastar a visão de mim com todas as minhas forças, e só consegui depois de muita luta. Decerto soltei um grito, pois isso me despertou do transe. (...) Azzo ainda estava ao lado da minha cama, e em seguida foi desaparecendo aos poucos dentro da bruma até sumir diante da porta! - (ANÔNIMO, 1853). (Grifo nosso)

O segundo aspecto recorrente é o definhamento paulatino da vítima. A vítima constantemente atacada durante a noite passa a definhar, enquanto sua doença é associada a algum mistério que médico nenhum consegue resolver.

A moça que antes florescia como uma rosa em sua beleza juvenil, vinha ficando a cada dia mais magra, enfermica e extenuada, e ao mesmo tempo tão pálida que no espaço de um mês não se notava sequer um matiz róseo em suas faces outrora resplandecentes- (ANÔNIMO, 1853). (Grifo nosso)

O terceiro aspecto é a explícita e poderosa influência que o vampiro exerce sobre os animais. Mais do que qualquer outro vampiro, a criatura stokeriana possui poderes sobrenaturais, exercendo influência sobre animais, particularmente os seres noturnos, como morcegos e lobos, e sobre algumas forças da natureza, como as marés e os ventos. Ele pode, inclusive, transformarse em fumaça. O maior de seus talentos é a leitura das mentes e a hipnose.

Assim que o estranho surgiu, os lobos interromperam sua perseguicão, tombaram uns sobre os outros e soltaram uivos pavorosos. $O$ estranho ergueu a mão e pareceu acená-la, com que os animais selvagens se arrastaram de volta para os arbustos como uma matilha de cães de caça rechaçados. - (ANÔNIMO, 1853). (Grifo nosso)

A quarta recorrência diz respeito ao passado humano do vampiro. $O$ vampiro stokeriano possui um passado humano de glórias em guerras e conquistas. Apesar de ser uma criatura abominável, enquanto homem, o vampiro suscita admiração.

Não tinha nenhuma figura esculpida, e a inscrição, que por toda parte consistia em um punhado de elogios lisonjeiros, nela era simples e sem adornos, contendo apenas as seguintes palavras: 'Ezzelin von Klatka pereceu como um cavaleiro na tomada do castelo. - (ANÔNIMO, 1853). (Grifo nosso) 
O quinto é a necessidade do vampiro ser convidado para adentrar a casa de suas vítimas. Esse é um fator interessante do vampiro stokeriano, ele não pode invadir as áreas habitadas por suas vítimas, ele deve ser, impreterivelmente, convidado a entrar. Depois disso, ele tem liberdade para entrar e sair quando e da maneira como bem entender.

\begin{abstract}
'Pois bem, então eu irei', disse ele, mais uma vez fixando seu olhar nela. 'Se em algum momento a minha companhia não lhe agradar, você terá de culpar a si mesma por travar conhecimento com alguém que raramente se impõe mas que é difícil de ser descartado." - (ANÔNIMO, 1853). (Grifo nosso)
\end{abstract}

O sexto aspecto da fase stokeriana é a existência de um estrangeiro que conhece todos os pormenores relativos à existência do vampiro. Essa é uma característica específica das personagens que se relacionam com o vampiro stokeriano. O conhecimento para aniquilar o mal e salvar os humanos das existência do vampiro está sempre nas mãos do europeu ocidental. Por mais que os moradores dos vilarejos afastados convivam com os vampiros, o conhecimento proferido por eles assume um ar supersticioso, enquanto com o estrangeiro ocidentalizado, esse conhecimento torna-se mais solene, quase científico.

\begin{tabular}{l} 
'Muito bem, senhorita', replicou ele voltando-se para ela e assumindo um \\
tom solene. 'Suplico-lhe, Franziska, para seu próprio bem e pelo amor \\
que você tem ao seu pai, que se apega a você com toda a sua alma, que \\
pondere bem as minhas palavras e que não me interrompa com \\
perguntas que eu não possa responder até que o trabalho seja \\
concluído. Sua vida está em grande perigo por causa da doença que lhe \\
aflige; com efeito você estará irremediavelmente perdida se não levar a \\
\hline cabo tudo aquilo que vou lhe participar agora. Prometa-me então fazer \\
estritamente como vou lhe dizer. - (ANÔNIMO, 1853). (Grifo nosso)
\end{tabular}

O sétimo diz respeito aos rituais para aniquilar o vampiro que tornam-se rigorosos e aproximam-se da religião. Há também a corrida contra o tempo. Esse é um ser que necessita de rituais específicos envolvendo, inclusive, aportes cristãos para seu aniquilamento. Poucas coisas são capazes de amedrontá-lo tanto quanto os símbolos religiosos. Além disso, o pôr e o raiar do sol funcionam como ampulhetas que controlam o tempo que a equipe tem para realizar o ritual.

\footnotetext{
'Então venha: é hora', replicou ele, conduzindo-a para a igreja. Os últimos raios de sol ainda escorriam através das janelas quebradas. (ANÔNIMO, 1853). (Grifo nosso)
}

Revista de Letras JUÇARA, Caxias - Maranhão, v. 02, n. 01, p. 312 - 331, jul. 2018 | 328 
O oitavo aspecto debruça-se sobre a mulher, vítima do vampiro, que assume importância vital no triunfo contra o mal. A mulher desempenha papel central na guerra contra o vampiro stokeriano. Por mais que ela seja a vítima natural da criatura, é ela que demonstra as condições para vencê-lo, chegando, em determinados casos, a operacionalizar o ritual de aniquilamento da criatura. Importante notar que, contra o vampiro stokeriano, o que prevalece é sempre o trabalho em equipe.

A agitação dentro do caixão se intensificou pavorosamente, como se alguma criatura viva estivesse tentando arrebentá-lo. O féretro era sacudido tal forma que ia se rachando e quebrando em todos os lados. Meio aturdida, Fanziska apanhou o terceiro prego. Não mais pensava em suas fraquezas, sabia apenas que estava correndo um perigo terrível, sem poder discernir de qual ordem seria. (...) ela martelou o terceiro prego com a mesma firmeza. - (ANÔNIMO, 1853). (Grifo nosso)

O último é a perpetuação da vida, o registro do final feliz e volta à normalidade. Os finais das histórias envolvendo o vampiro stokeriano ocorrem com o registro da volta à normalidade $\mathrm{e}$, mais do que isso, o amor entre um casal humano revela-se como o instrumento para perpetuação da vida.

Quão alegre não foi a surpresa do Cavaleiro de Fahnenberg quando sua filha e Franz pediram sua benção e manifestaram seu desejo de se unirem no mesmo dia! Esse dia logo chegou, e viu os olhares radiantes de dois casais felizes. - (ANÔNIMO, 1853). (Grifo nosso)

Como se vê, a partir do destaque das três fases do vampiro ao longo da literatura é que por razão da permutabilidade do tema, tal qual preconizada por Propp e apresentada no início desse artigo, os padrões da personagem, de sua função na trama e seus cacoetes de performance foram sendo carregados para outras etapas, de forma que essa automaticidade deu, então, espaço que novos padrões fossem sendo criados em torno do vampiro, na fase subsequente. Como resultado, em Drácula (STOKER 1897), há a condensação de todas as fases anteriores, perpetuando estereótipos e vícios de performance por toda a mediação da personagem ao longo do século XX e início do XXI.

\section{VAMPIRES IN THE LITERATURE: \\ A RESEARCH ON CARACTHER'S PERFORMANCE PATTERN BY THE PERMUTABILITY OF THEME.}


ABSTRACT: Vampires have been part of the horror stories. In this journey, male blood sucking creatures began to show not only stereotyped physical complexion, but mainly, performances that delimit the protagonism and determine the function of these characters. The aim of this study is to propose a classification of vampires in literature, to understand how the permutability of the vampire theme conformed the performances through horror literature, culminating in Bram Stoker's Dracula of 1897, as a novel responsible for the transmutation of the vampire character from literature to cinema and reference to what is meant by vampire today. The classification was made from eight texts, that emphasizes three phases of the vampire in literature: the folkloric vampire, the byronian vampire and the stokerian vampire. Each of these phases carries contributions from the previous phase, being the gothic romanticism of the XVIII and XIX centuries is the last stage encompassed in this text. The premise for the proposed survey is the theory on the permutability of the essentials themes, proposed by Vladimir Propp for the study of the morphology of the folktales. This study is a shortcut from an extensive research that used lots of texts to establish the classification criteria. Here are presented the most relevant in the understanding of these vampire figures perpetuated by the fantastic horror stories.

KEYWORDS: Vampire. Horror. Permutability of the theme. Romanticism. Gothic literature.

\section{REFERÊNCIAS BIBLIOGRÁFICAS}

ARGEL, Martha. NETO, Humberto Moura (ORG.). O Vampiro Antes de Drácula. São Paulo: Aleph, 2008

BYRON, Lord. "The Giaour - O Infiel (excerto) - 1813". In Caninos: antologia do vampiro literário. São Paulo: Berlendis \& Vertecchia, 2010.

"Augustus Darvell (Fragmentos de uma novela) - 1819". In Caninos: antologia do vampiro literário. São Paulo: Berlendis \& Vertecchia, 2010.

CALMET, Augustin. "Dissertação sobre os Regressantes em corpo, os Excomungados, os Upiros ou Vampiros, Brucolaques etc - 1746". In Caninos: antologia do vampiro literário. São Paulo: Berlendis \& Vertecchia, 2010.

CARPEAUX, Otto Maria. História da Literatura Ocidental. Volumes 2 e 3. São Paulo: Leya, 2012

GÓGOL, Nikolai. “Vii - 1835”. In Caninos: antologia do vampiro literário. São Paulo: Berlendis \& Vertecchia, 2010.

KILGOUR, Maggie. The Rise of the Gothic Novel. New York: Routledge, 1997.

KLINGER, Leslie S. The New Annotated Dracula. New York: W.W. Norton \& Company Inc, 2008.

LOVECRAFT, H.P. O Horror Sobrenatural em Literatura. São Paulo: lluminuras, 2007

MÉRIMÉE, Prosper. "A Guzla (excerto) - 1827". In Caninos: antologia do vampiro literário. São Paulo: Berlendis \& Vertecchia, 2010.

MILLER, Elizabeth. "Shapeshifting Dracula: The Abridged Edition 1901" in The Fantastic Vampire: Studies in the children of the night: selected essas from the 
Eighteenth International Conference on the Fantastic in the Arts. Santa Barbara: Greenwood, 2002.

OSSENFELDER, Henrich August. "Crê a Moça Minha Amada (O Vampiro) 1748". In Caninos: antologia do vampiro literário. São Paulo: Berlendis \& Vertecchia, 2010.

POLIDORI, John William. "O Vampiro - 1819". In Caninos: antologia do vampiro literário. São Paulo: Berlendis \& Vertecchia, 2010.

PRAZ, Mario. A Carne, a Morte e o Diabo na Literatura Romântica. Campinas: Editora da Unicamp, 1996.

PROPP, Vladimir. Morfologia do Conto Maravilhoso. Rio de Janeiro: Forense Universitária, 2006.

STOKER, Bram. "O Convidado de Drácula - 1890/1897". In O Vampiro Antes de Drácula. São Paulo: Aleph, 2008. . Drácula. Rio de Janeiro: Ediouro, 2009.

TOLSTOI, Alexei. "A Família do Vurdalak - 1847". In O Vampiro Antes de Drácula. São Paulo: Aleph, 2008.

ANÔNIMO. "O Estranho Misterioso - 1853". In Caninos: antologia do vampiro literário. São Paulo: Berlendis \& Vertecchia, 2010.

Data da Submissão: 30/04/2018

Data da Aprovação: 24/07/2018 